\title{
Advancement of laparoscopic surgery in Guyana: a working model for developing countries
}

This article was published in the following Dove Press journal:

Advances in Medical Education and Practice

25 October 2016

Number of times this article has been viewed

\author{
Shamir O Cawich' \\ Cheetnand Mahadeo ${ }^{2}$ \\ Madan Rambaran ${ }^{2}$ \\ Sheik Amir ${ }^{2}$ \\ Shilindra Rajkumar ${ }^{2}$ \\ Ivor W Crandon' \\ Vijay Naraynsingh' \\ 'Department of Clinical Surgical \\ Sciences, University of the West \\ Indies, St Augustine Campus, Trinidad \\ and Tobago; ${ }^{2}$ Department of Surgery, \\ Guyana Public Hospital Corporation, \\ Georgetown, Guyana
}

Correspondence: Shamir O Cawich Department of Clinical Surgical Sciences, University of the West Indies, St Augustine Campus, Trinidad and Tobago $\mathrm{Tel}+\mathrm{I} 8686229909$

Email socawich@hotmail.com
Abstract: In the late 20th century, the volume and complexity of laparoscopic operations being performed have increased worldwide. However, surgical practice lagged behind in the Caribbean region. This article reports a tailored approach to initiate advanced laparoscopy in Guyana, which can be used as a model to initiate laparoscopic services in other developing nations. This can be achieved in four stages: 1) relying on regional proctors to teach laparoscopic techniques adapted to resource-poor environments, 2) focusing on developing skill sets such as laparoscopic suturing in order to rely less on expensive consumables, 3) creating partnerships that include all stakeholders, and 4) collaborating with regional experts as a valuable resource for continued medical education, multidisciplinary support, and sharing learning experiences. Keywords: laparoscopy, education, Caribbean, minimal, invasive

\section{Introduction}

Guyana is the largest English-speaking country in the Caribbean region. ${ }^{1}$ In this region, there are many challenges to health care delivery that have already been documented. ${ }^{2} \mathrm{An}$ example can be seen in minimally invasive surgical (MIS) practice, since the first laparoscopic cholecystectomy in Guyana was recorded in $2002 ;{ }^{3}$ the national case volume remained low at an average of three cases per month (Cawich, unpublished data, 2012).

Surgical leaders recognized that there was a need to improve MIS practice in Guyana. In order to achieve this, they formed a lobby team with a mandate to introduce advanced laparoscopic surgery in Guyana. This report documents the challenges encountered when advanced laparoscopic practice was introduced and the mechanisms used to overcome these obstacles. The information in this report can be used as a guide to implement MIS practice in other developing nations that may face similar challenges in health care delivery.

\section{Methods}

After recognizing the need, surgical leaders formed a lobby team with a mandate to implement advanced laparoscopic surgery in Guyana. The lobby team approached this task in a systematic manner. They first engaged in a round-table discussion to identify existing obstacles to MIS practice. This information was supplemented by informal interviews with local health care workers to understand their views on the introduction of MIS practice. Specifically, health care workers were invited to comment on any limitations to the introduction of MIS practice in the local health care environment. 
Recognizing that a full understanding of the local health care climate was necessary to devise the blueprint for advanced MIS practice, the lobby group planned to discuss the details of any obstacle identified via the round-table exercise and/or health care workers' interviews. The second stage was to preemptively identify solutions to obstacles that could arise during the implementation stage.

In the third stage, the lobby team would identify and attempt to engage all stakeholders involved in surgical care in Guyana. This included hospital administrators, distributors of laparoscopic supplies, and relevant training institutions.

In the final stage, with support from all stakeholders, the lobby team would then organize a laparoscopic workshop in order to stimulate interest in laparoscopy in Guyana. It was hoped that success of these short-term plans could demonstrate that MIS practice was feasible and would stimulate continued development of MIS practice in Guyana.

The outcomes of these interventions and the impact on MIS practice in Guyana are described. Also, the methods used to stimulate MIS practice in this setting are described so that they can be used as a guide to implement laparoscopic surgery in other developing nations that may face similar challenges in health care delivery.

\section{Results}

Three major obstacles were identified through the roundtable exercise and informal interviews with local health care workers: 1) the development of advanced laparoscopy had not been prioritized by policy makers to this point; 2 ) laparoscopic consumables were not routinely available in the public hospital system as their cost was often prohibitive; and 3) few local surgeons could perform basic operations but had not yet accrued the necessary skill sets for advanced laparoscopic procedures. The lobby team discussed each of these issues individually and formulated a plan to address each consideration, as outlined subsequently.

Seven major stakeholders in regional health care delivery were identified: 1) the University of Guyana (UG) - a local tertiary medical educational institution, 2) the Georgetown Public Hospital Corporation (GHPC) - the administrative body for the national tertiary referral hospital in Guyana, 3) the University of the West Indies (UWI) - a regional tertiary university serving the Caribbean, 4) the Caribbean College of Surgeons (CCOS) - a general surgical society in the region, 5) the Caribbean Society of Endoscopic Surgeons (CaSES) - a professional society of advanced MIS surgeons in the region, 6) AA Laquis Ltd (Port of Spain, Trinidad and Tobago), and 7) Bryden Pi Ltd (Port of Spain, Trinidad and Tobago) - regional distributors of MIS supplies.
The lobby group formally approached each of the major stakeholders, engaging them in dialogue to outline the plans to develop MIS practice. The lobby group disclosed their plans to organize a hands-on laparoscopic workshop in Guyana in order to demonstrate the ability to perform MIS operations in the existing health care environment. It was hoped that the laparoscopic workshop would demonstrate feasibility of MIS practice in the short term and would stimulate its continued development in Guyana in the long term.

The following specific interventions were undertaken to address each consideration arising at the round-table exercise and/or health care worker interviews.

\section{Prioritization of advanced laparoscopy by policy makers}

The lobby team approached administrators at the GHPC who were responsible for policy implementation and health care delivery at the main tertiary referral hospital. They outlined the societal value and patient benefits that were expected from an MIS service at this facility. The administration was receptive in principle and agreed to participate in a laparoscopic workshop to stimulate interest in MIS practice. The GHPC agreed to provide access to their operating theaters, hospital facilities, and conference rooms for this purpose. The local surgical teams participated by identifying suitable patients from the hospital who were willing to participate.

\section{Prohibitive cost of laparoscopic consumables}

The lobby team met the main regional distributors of MIS supplies (AA Laquis Ltd and Bryden Pi Ltd) to discuss MIS development in Guyana and methods to address the high cost of consumables. Several avenues of potential cost savings were discussed, including hardware donations, provision of consumables on consignment, and/or facilitation of training and educational activities. Local distributors also demonstrated their commitment to regional development by providing consumables and sponsorship for a hands-on workshop for Guyanese surgeons at no cost.

Another way that the lobby group planned to manage the cost of consumables was to avoid heavy reliance on the use of these products. Practicing surgeons in the Caribbean region were invited to serve as proctors for the laparoscopic workshop because they routinely work in similar resourcepoor environments. There was significant participation from the regional stakeholders, with logistic and technical support 
coming from the medical educational institutions - UG and UWI. The academic content and human resources necessary for the laparoscopic workshop were mobilized by the regional professional societies - CaSES and CCOS. The regional distributors - AA Laquis Ltd and Bryden Pi Ltd - contributed the requisite laparoscopic supplies and sponsorship. And the GHPC provided access to their facilities and clinical services.

\section{Proctorship for advanced laparoscopic skill sets}

The lobby team in collaboration with the seven major stakeholders planned and executed a hands-on workshop on June 6, 2014 (Figure 1). This workshop had a heavy focus on advanced laparoscopic techniques adapted to the resource-poor environment. The workshop organizers deliberately invited regional experts as proctors and insisted on the use of existing equipment at the GHPC for the workshop. This was done to demonstrate to local health care provider teams that advanced MIS operations were feasible in Guyana using the existing equipment, with some modifications in surgical techniques.

The workshop comprised didactic lectures, round-table discussions, and proctorships in specific techniques. There were four operations performed by Guyanese surgeons under the proctorship of the primary author: single incision cholecystectomy (Figure 2), multiport ventral hernia repair, transabdominal preperitoneal inguinal herniorrhaphy, and totally extraperitoneal hernia repair.

The patients were carefully selected from the hospital waiting lists. For this training exercise, patients $<50$ years of age, without prior abdominal operations, body mass indices $<30$, and ASA (American Society of Anesthesiologists) scores of 1-2, were selected. The operations were completed

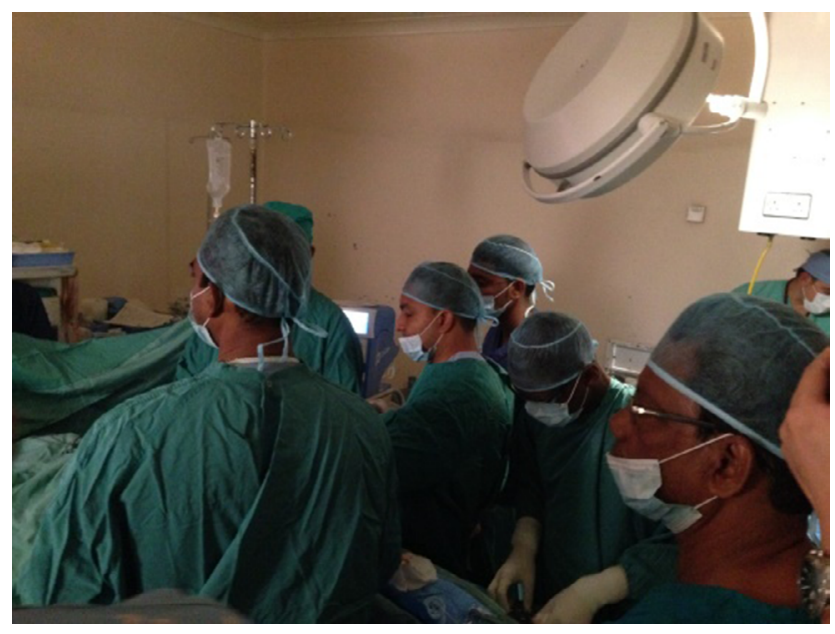

Figure I Operating room proctorship in single incision laparoscopic cholecystectomy at the Georgetown Public Hospital Corporation on July 6, 2014.

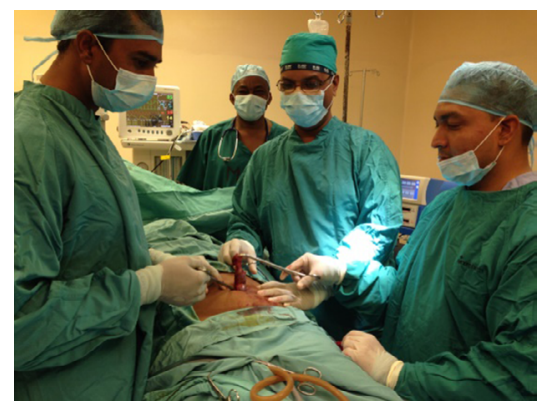

Figure 2 Photograph of the first recorded single incision laparoscopic cholecystectomy to be performed in Guyana.

Note: The surgeons (from left to right: Mahadeo C, Amir S, and Cawich SO) extract the gallbladder via the umbilicus.

by local surgeons under the proctorship of a visiting proctor who was present during the operations.

There was a mixture of cases performed during the workshop. There were no perioperative complications or mortality reported. The patients were all discharged within 24 hours of operation with minimal postoperative pain. After follow-up for 12 months, no early recurrences were noted in the patients after hernia repair.

This event was a significant milestone for MIS practice in Guyana because all operations were performed for the first time in Guyana. More importantly, the surgeons were proctored in modified techniques suited to their environment. And, although not directly quantifiable, there was general sentiment of improved working relationships between the stakeholders.

An audit of the GHPC operating register after the workshop revealed that there were 98 laparoscopic operations performed over the subsequent 12 months: 94 laparoscopic cholecystectomies, two inguinal hernia repairs, one ventral hernia repair, and one staging laparoscopy. This amounted to an average case volume of eight per month in the subsequent year after the workshop - an increase from the previous national average of three cases per month. The cases were performed with good outcomes: 12 conversions (12\%), two $(3 \%)$ perioperative complication (surgical site infections $\times 2$ and bleeding $\times 1$ ), and no deaths recorded.

\section{Discussion}

In Guyana, a major obstacle to surgical health care delivery was the high rate of outward migration of skilled health care workers. $^{2}$ In response to this, surgical leaders in Guyana pioneered a postgraduate training program in $2006 .^{2}$ It was hoped that this would reduce specialist attrition rates, thereby improving surgical care in the long term. Fourteen surgeons graduated from the program within 8 years of its commencement. ${ }^{4}$ Although the number of practicing surgeons in Guyana increased, the range of surgical services remained limited. 
Since the 1990s, there was a global thrust toward laparoscopic surgery that was shown to improve surgical outcomes, ${ }^{5}$ but this was not realized in Guyana. The first recorded laparoscopic operation in Guyana was a cholecystectomy performed by Persaud and Amir in 2002 at a private hospital. ${ }^{3}$ The first laparoscopic operation in the public health care system was recorded in 2007 at the GHPC. ${ }^{3}$ This was made possible by a donation of US\$60,000 worth of laparoscopic equipment from the People's Republic of China. ${ }^{3}$ The operation was a laparoscopic cholecystectomy performed by Doctor Beijing Fu, a visiting surgeon from the People's Republic of China. ${ }^{3}$

The generous donation from the People's Republic of China contributed greatly to surgical care in Guyana. Local surgeons were exposed to basic techniques and now had access to laparoscopic hardware. The local surgeons continued to perform laparoscopic operations, but it was limited to laparoscopic cholecystectomies ${ }^{6}$ and limited to low case volumes, with a national average of three cases per month (Cawich, unpublished data, 2012).

Surgical leaders in Guyana recognized the need to expand the range of laparoscopic services being offered, prompting the creation of a common-interest lobby group. As a part of their strategic plan for promotion of MIS practice, the lobby group engaged all the stakeholders identified in the roundtable exercise. This was an important aspect of the strategic plan so that no party felt marginalized and all stakeholders had the satisfaction of having contributed to the positive outcomes from this exercise.

The importance of health care workers' involvement was recognized. ${ }^{7}$ Therefore, local health care workers were consulted and invited to give their views on the initiation of advanced laparoscopy. Specifically, they were invited to comment on the perceived limitations in the local health care environment. The local surgeons reiterated what was already known, that is, limited skill sets and expensive consumables were the main limitations. But by involving the health care workers at this stage, it encouraged them to become a part of the process early and encouraged them to work together toward a common goal.

The round-table exercise and health care worker interviews were important steps in the strategic plan because they allowed existing limitations to be identified preemptively. When the plans were presented to the stakeholders during the engagement process, any considerations raised at that stage were easy to address because they were already discussed thoroughly at a previous stage.
The three major obstacles that were identified were addressed in a systematic fashion as outlined subsequently.

\section{Prioritization of advanced laparoscopy by policy makers}

During the engagement process, the lobby group approached stakeholders with a strategic plan for development of MIS practice, which included a comprehensive plan to address any limitations that may have arisen in the implementation phase. Together with the well-recognized patient advantages, institutional benefits and societal value that were expected from an MIS service, policy makers began to develop awareness and interest. With the recognition that major national and regional stakeholders were involved, administrators at the GHPC who were responsible for policy implementation and health care delivery began to prioritize development of MIS practice.

The GHPC administration was receptive, especially since the benefits of laparoscopy were well documented in neighboring Caribbean territories. ${ }^{8-14}$ The lobby group asked the GHPC to demonstrate their commitment by hosting the laparoscopic workshop in Guyana.

\section{Prohibitive cost/nonavailability of laparoscopic consumables}

It was not difficult to engage the regional MIS supply distributors because they had a genuine interest in health care development as a part of their mission statement. There was also the corollary economic reward if advanced laparoscopic practice became sustainable in Guyana. Therefore, the regional distributors were eager to demonstrate their commitment. In this instance, they demonstrated this commitment providing consumables and sponsorship for the hands-on workshop at no cost.

The local distributors were eager to demonstrate their commitment to development of sustainable MIS practice by discussing several avenues of potential cost savings, including hardware donations, provision of consumables on consignment, and continued facilitation of training and educational activities. In the long term, plans were prospectively put in place to support continued workshops on a 2-yearly basis to stimulate continued development and ensure sustainability. The exemplary participation from MIS distributors was unexpected, but it reinforced the value of dialogue and inclusiveness in the strategic planning process.

The lobby group recognized that the cost of consumables for advanced laparoscopy was a major limitation 
across the entire Caribbean region. ${ }^{5}$ They also recognized that surgeons in the Caribbean had become innovative in order to reduce the number of consumables required for laparoscopic operations. ${ }^{8-14}$ This included the use of reusable trocars/instruments, ${ }^{8-11}$ use of laparoscopic suturing ${ }^{13}$ instead of staples or clips, and modification of surgical techniques to suit low-resource settings. ${ }^{11-13}$ Therefore, a deliberate attempt was made to invite Caribbean surgeons as proctors for laparoscopy in Guyana. That way, local surgeons learned techniques that were well suited to their environment rather than learning techniques used in resource-rich environments that relied heavily on instrumentation and consumables. The lobby group took advantage of several avenues - such as the CCOS, CaSES, and regional medical universities - to access a ready supply of regional experts to proctor Guyanese surgeons in advanced laparoscopy.

\section{Need for improvement in advanced laparoscopic skill sets}

The lobby team, in collaboration with the seven stakeholders, identified, planned, and executed the hands-on workshop on June 6, 2014 (Figure 1). The workshop had a heavy focus on advanced laparoscopic techniques adapted to the resourcepoor environment. Therefore, the organizers deliberately utilized existing equipment at the GHPC in order to demonstrate that advanced operations could be performed using the existing equipment, with some modifications in surgical techniques.

The workshop comprised didactic lectures, round-table discussions, and proctorships in specific operative procedures. There was measurable success as a result of this workshop. These operations were recorded for the first time in Guyana - all performed by Guyanese surgeons under proctorship by the primary author. Equally important, the surgeons were proctored in modified techniques suited to their environment. It was hoped that the Guyanese surgeons' experiences would contribute to sustainable development of MIS in Guyana.

Another measure of success was the continued performance of laparoscopic operations. Although all the operations performed after the workshop were not advanced operations, it was notable that there was an increase in case volume from a national average of three cases to eight cases per month in the subsequent year. The recorded outcomes were good with acceptable morbidity and mortality rates. Although conversion rates were high at $12 \%$, this was likely because the surgeons were cautious during their early experience. Therefore, the conversions were not considered as complications - but good surgical judgment in this early experience.

Other markers of success were also seen. Although it could not be readily quantified, there was a notable improvement in working relationships between all stakeholders. This allowed continuity of planned proctorships, provision of multidisciplinary support, and encouragement for local surgeons to develop their laparoscopic skill sets.

\section{Conclusion}

The introduction of advanced laparoscopy in Caribbean countries requires a tailored approach. Specifically, we must rely on regional proctors who use laparoscopic techniques adapted to the resource-poor environment. Local surgeons must also focus on developing laparoscopic skill sets in order to rely less on expensive consumables. Dialogue and partnership with policy makers, distributors of consumables, and local health care teams are the cornerstones in implementing advanced laparoscopy in the Caribbean. In addition, creating partnerships with regional surgeons is an invaluable resource for continued medical education, multidisciplinary support, and sharing learning experiences.

\section{Disclosure}

The authors report no conflicts of interest in this work.

\section{References}

1. Naraynsingh V, Bahadursingh S, Maharaj R, Harnarayan P, Cawich SO. Surgery in the West Indies: a perspective from Trinidad. Curr Med Res Prac. 2014;4:1126-1129.

2. Cameron BH, Rambaran M, Sharma DP, Taylor RH. The development of postgraduate surgical training in Guyana. Can J Surg. 2010;53(1): 11-16.

3. Landmark Surgery at Mercy Hospital. Stabroek News. 2002 November 27. Available from: http://www.landofsixpeoples.com/news022/ ns211277.htm. Accessed September 18, 2016.

4. Cameron BH, Martin C, Rambaran M. Surgical training in Guyana: the next generation. Can J Surg. 2015;58(1):7-9.

5. Dan D, Nararynsingh V, Cawich SO, Jonnalagadda R. The history of laparoscopic general surgery in the Caribbean. West Indian Med J. 2012;61(4):465-469.

6. Guyana Times. Georgetown Public Hospital now performing laparoscopic surgery; 2013. Available from: http://www.kaieteurnewsonline. com/2013/05/01/gphc-equipped-to-perform-laparoscopic-surgery/. Accessed February 12, 2014.

7. Cawich SO, Johnson PB, Dan D, Naraynsingh V. Surgical leadership in the time of significant generational diversity. Surgeon. 2014;12(4): 235-236.

8. Cawich SO, Wilson C, Simpson LK, Baker AJA. Stump cholecystitis: laparoscopic completion cholecystectomy with basic laparoscopic equipment in a resource poor setting. Case Rep Med. 2014;787631:1-4.

9. Cawich SO, Albert M, Singh Y, et al. Single incision laparoscopic cholecystectomy in the anglophone Caribbean: a multi centre audit of regional hospitals. Int J Biomed Sci. 2014;10(3):191-195.

10. Cawich SO, Mohanty SK, Simpson LK, Bonadie KO. Is emergent laparoscopic cholecystectomy for acute cholecystitis safe in a low volume resource poor setting? Int J Surg. 2014;12(8):798-802. 
11. Cawich SO, Thomas D, Hassranah D, Naraynsingh V. Evolution of single incision laparoscopic cholecystectomy in the Caribbean: toward conventional instruments without working ports. Case Rep Surg. 2014;164342:1-4.

12. Cawich SO, Murphy T, Shah S, et al. Endoscopic transmural drainage of pancreatic pseudocysts: technical challenges in the resource poor setting. Case Rep Gastrointest Med. 2013;942832:1-6.
13. Cawich SO, Mohanty SK, Simpson LK, Ramdass MJ, Naraynsingh V. Is laparoscopic appendectomy safe when performed in a low volume setting? Int J Biomed Sci. 2014;10(1):31-35.

14. Cawich SO, Johnson PB, Shah S, et al. The multidisciplinary team approach to hepatobiliary diseases: a working model in the Caribbean setting. J Multidiscip Healthc. 2014;7:227-230.

\section{Publish your work in this journal}

Advances in Medical Education and Practice is an international, peerreviewed, open access journal that aims to present and publish research on Medical Education covering medical, dental, nursing and allied health care professional education. The journal covers undergraduate education, postgraduate training and continuing medical education including emerging trends and innovative models linking education, research, and health care services. The manuscript management system is completely online and includes a very quick and fair peer-review system. Visit http://www.dovepress.com/testimonials.php to read rea quotes from published authors.

Submit your manuscript here: http://www.dovepress.com/advances-in-medical-education-and-practice-journal 